DOI: http://dx.doi.org/10.12660/gvcasosv4n2c11

\title{
PRIDIA: O DESAFIO DA EXPANSÃO DE UMA MICROEMPRESA DE COBERTURA DE FESTAS UNIVERSITÁRIAS ${ }^{1}$ \\ Pridia: the expansion challenge of a micro-enterprise that covers university parties
}

KAVITA MiadaiRa HaMZA - kavita@usp.br

Faculdade de Economia, Administração e Contabilidade da Universidade de São Paulo - São Paulo, SP, Brasil

\section{Resumo}

Os sócios da Pridia precisam decidir sobre os planos de expansão da empresa: expandir o negócio para outras cidades ou integrar a cadeia de valor?

O caso pode ser utilizado em diferentes cursos de graduação relacionados a estratégias de crescimento, estratégias competitivas, análise da demanda, segmentação, diferenciação e posicionamento de mercado.

Palavras-chave: Estratégia, Marketing, Plano de Expansão, Posicionamento de marca, Segmentação de mercado.

\begin{abstract}
Pridia's partners need to decide on the company's expansion plans: whether to expand the business to other cities or integrate the value chain?
\end{abstract}

The case can be used on different graduate courses related to growth strategies, competitive strategies, demand analysis, segmentation, differentiation and market positioning.

Keywords: Strategy; Marketing; Expansion Plan; Brand Positioning; Market Segmentation.

Criada em setembro de 2012 pelos alunos de graduação Vitor Ballaben (Administração na FEA-USP), Lucas Olivetti (Administração na FGV-EAESP) e Roberto Coutinho (Ciências da Computação na UFABC), a Pridia é uma empresa especializada na cobertura fotográfica e audiovisual de festas universitárias. Com menos de um ano de existência, já realizou cerca de 300 trabalhos em grandes eventos, abarcando $50 \%$ de seu potencial de mercado no Estado de São Paulo. Vitor, Lucas e Roberto já superaram diversas dificuldades neste curto período de existência, mas não podem parar e continuar onde estão. O mercado é dinâmico, os atuais concorrentes tentarão conseguir de volta uma fatia do mercado, e novos concorrentes podem aparecer. Assim, eles sabem que agora o grande desafio que têm pela frente é pensar sobre o crescimento da empresa.

Nas últimas semanas, os sócios levantaram muitas informações de mercado. Agora estão vivenciando o seguinte dilema: como crescer? Expandir seu negócio para outras cidades (Rio de

\footnotetext{
${ }^{1}$ A criação deste caso foi possível devido à cooperação dos fundadores da Pridia: Vitor Ballaben, Lucas Olivetti e Roberto Coutinho.
} 
PRIDIA: O DESAFIO DA EXPANSÃO DE UMA MICROEMPRESA DE COBERTURA DE FESTAS UNIVERSITÁRIAS

Kavita Miadaira Hamza

Janeiro e/ou Belo Horizonte), cujo potencial para a empresa representa um crescimento de cerca de $43 \%$ no número de eventos? Ou integrar a cadeia de valor, criando uma nova empresa, especializada na produção de festas universitárias, com potencial de crescimento em torno de $75 \%$ no faturamento?

Seria ótimo poder aproveitar todas as oportunidades de mercado, mas a empresa ainda é pequena e tem sua gestão centralizada nos três sócios fundadores. Eles sabem que, se tentassem abarcar as duas propostas, poderiam perder a alta qualidade de seu negócio atual, que já tem uma boa reputação de mercado e que atualmente produz um importante fluxo de caixa para manter o negócio.

\section{Fotos profissionais em festas universitárias}

O mercado de fotos profissionais em festas universitárias de São Paulo é recente, tendo sido iniciado em 2008, com a entrada de duas empresas nesse ramo de negócios. Até então, as opções que os organizadores (diretórios, centros acadêmicos, atléticas e produtoras de eventos) tinham eram:

(i) Não realizar a cobertura fotográfica das festas;

(ii) Fazer eles próprios a cobertura das festas, com fotos amadoras;

(iii) Contratar fotógrafos autônomos para uma cobertura mais profissional.

Em 2008 surgiram duas empresas, cuja proposta era realizar a cobertura fotográfica de modo profissional: Salseiro e Eu Vip. Como se tratava de um novo mercado, era necessário um grande esforço de vendas para convencer os organizadores das festas de que valia a pena investir nas fotos profissionais. Para ganharem uma fatia maior do mercado, iniciaram uma guerra de preços, e, depois de alguns meses, ambas as empresas estavam fazendo as coberturas fotográficas gratuitamente aos clientes. A receita dessas empresas advinha somente de outros negócios, e parte era investida no segmento de festas universitárias.

Logo depois, outras duas empresas passaram a oferecer o mesmo serviço, também de maneira gratuita: Edu Carioca e Blacktag. Como já havia dois concorrentes no mercado que realizavam a cobertura fotográfica gratuitamente, essas novas empresas entraram nesse mercado já oferecendo seus serviços dessa forma.

Atualmente a Salseiro não possui a mesma força que já teve nesse mercado, e, pelo número reduzido de eventos com que trabalha, possui atualmente apenas um fotógrafo em sua equipe. Em 2012, cobriu cerca de 30 eventos universitários, número que praticamente não mudou em 2013. O website (www.salseiro.com.br) traz, além das fotos, matérias sobre os eventos que cobre e sobre outros assuntos tão diversos quanto sustentabilidade, vestibular, carreira, oportunidades de estágio, jogos universitários e atualidades. Entretanto, devido à sua pouca atratividade, possui uma quantidade de acessos praticamente nula.

A Eu Vip foi criada em 2008, com o objetivo de ser o maior portal universitário da cidade. No entanto, em 2012 encerrou as atividades. O website (www.euvip.com.br) deixou de existir, e as últimas publicações feitas na fanpage do Facebook (www.facebook.com/FanEuvip) e no Twitter (twitter.com/euvip), que conta com 737 seguidores, foram em 6 de junho de 2012.

A Edu Carioca foi criada em 1996, e seu negócio é focado principalmente na divulgação de marcas e eventos, bem como a venda de ingressos para festas e eventos voltados para o público jovem/universitário. Sua principal região de atuação é São Paulo. Apesar de existir desde 1996, foi só a partir de 2009 que decidiu entrar para o ramo da cobertura fotográfica das festas universitárias em São Paulo. A empresa é mais conhecida pelo público em geral pela cobertura de baladas sertanejas, micaretas e escolas de samba. Em 2012, cobriu cerca de 170 eventos, dos quais apenas em torno de 60 eram festas universitárias. Já em 2013, dos cerca de 110 eventos, apenas 40 tratavamse de festas universitárias. O website (www.educarioca.com.br) traz informações sobre agenda de baladas, venda de ingressos, fotos das festas de que fazem a cobertura, guia de bares, cursos (barista, fotógrafo, workshop de caipirinhas, cervejas especiais, garçom e bartender) e notícias diversas (porém com maior foco em baladas e artistas). 
PRIDIA: O DESAFIO DA EXPANSÃO DE UMA MICROEMPRESA DE COBERTURA DE FESTAS UNIVERSITÁRIAS

Kavita Miadaira Hamza

Já a Blacktag surgiu em março de 2012, com o propósito de realizar coberturas fotográficas de festas universitárias. Em 2012, cobriu cerca de 40 eventos, número que subiu para cerca de 70 em 2013. A empresa possui um website contendo informações sobre os próximos eventos universitários, a venda de ingressos e uma teórica galeria de fotos. Entretanto, as informações sobre os eventos são nada mais do que a própria cópia do evento oficial no Facebook, não trazendo nada adicional. A comercialização de ingressos não possui uma estrutura e ainda não se realizam vendas expressivas, algo que dificilmente virá a acontecer pela forte e focada concorrência já existente nesse mercado. Por fim, a galeria de fotos é formada apenas por links que redirecionam o cliente para a fanpage no Facebook (www.facebook.com/blacktag.oficial), que conta com mais de nove mil likes, adquiridos de modo não convencional (compra).

\section{O surgimento da Pridia e seu diferencial de mercado}

A entrada da Pridia no mercado de fotos universitárias profissionais se deu em setembro de 2012, e seu principal nicho de atuação são as festas universitárias voltadas para os públicos das classes A e B, de 17 a 25 anos. Assim como a Edu Carioca e a Blacktag, precisou entrar no negócio fazendo a cobertura fotográfica gratuitamente, para conhecer melhor como estava estruturado e como funcionavam esse mercado, os organizadores e os concorrentes, e também para que o mercado a conhecesse.

Logo no início, notou que o mercado de fotos se dividia basicamente em (i) fotos com boa qualidade, porém que demoravam em torno de quatro dias para serem publicadas, ou (ii) fotos que eram publicadas com bastante agilidade (em geral, logo no dia seguinte à realização da festa), porém com baixa qualidade e inexistente edição. Como comparação, veja, nos Anexos 1 e 2, exemplos que mostram a diferença de qualidade entre duas fotos tiradas na mesma festa universitária. As fotos da direita nitidamente possuem uma qualidade mais alta que as da esquerda, com maior nitidez, detalhes e cores mais vivas, diferenciando e caracterizando uma foto profissional. Também na segunda ilustração, trata-se de um mesmo local, na mesma festa universitária.

Foi então que os sócios perceberam que havia uma boa lacuna a ser preenchida: a de fotos com alta qualidade, publicadas com bastante agilidade. Para obter as fotos com alta qualidade, precisaram investir na profissionalização dos fotógrafos e cinegrafistas, e também na aquisição de equipamentos altamente especializados. Dessa forma, conseguiram mostrar seu diferencial aos clientes (diretórios, centros acadêmicos, atléticas e produtoras de eventos), que enxergaram um alto valor no serviço prestado e aceitaram pagar por uma cobertura fotográfica com tal nível de qualidade. Atualmente, são raras as exceções na qual ainda prestam o serviço de maneira gratuita, o que é feito especialmente na abertura de novos clientes. Na maior parte das festas que cobrem, um ou outro concorrente também está presente, fazendo a cobertura gratuitamente. Mesmo assim, seus clientes acham vantajoso contratar os serviços da Pridia.

O mercado de festas universitárias, como um todo, se profissionalizou nos últimos anos. Hoje, em muitos casos, os eventos são organizados por produtoras de eventos e agências de festas, que são contratadas pelos diretórios/centros acadêmicos e atléticas das universidades. Quando tais produtoras e agências são pressionadas para reduzir custos, sugerem que a cobertura fotográfica seja feita por uma empresa que não cobra pelo serviço. No entanto, a Pridia conseguiu criar um diferencial e posicionamento tão forte no mercado, que, em muitos casos, os diretórios/centros acadêmicos e atléticas não aceitam abrir mão de seus serviços.

Em 2012, a Pridia cobriu 79 festas universitárias, e em 2013 esse número chegou a 288 eventos, um impressionante crescimento de $265 \%$. O Anexo 3 mostra o número de eventos cobertos pela Pridia em 2013, e o Anexo 4 apresenta a participação de mercado dos principais competidores em 2012 e 2013. É possível notar um excepcional crescimento da Pridia, que dobrou sua participação de mercado, enquanto a Blacktag, seu principal concorrente, avançou apenas quatro pontos percentuais. Com apenas um ano de vida, a empresa já cobriu mais eventos universitários do 
PRIDIA: O DESAFIO DA EXPANSÃO DE UMA MICROEMPRESA DE COBERTURA DE FESTAS UNIVERSITÁRIAS

Kavita Miadaira Hamza

que todos os seus concorrentes somados. Sua fanpage no Facebook (www.facebook.com/pridia) já tem mais de 20 mil curtidas, mais que o dobro da Blacktag. Também em número de usuários, o crescimento é expressivo: $467 \%$ entre janeiro e dezembro de 2013, conforme o Anexo 5. Para atender tal demanda sem perder a qualidade e a agilidade, a empresa já conta com uma equipe formada por mais de 15 profissionais, entre fotógrafos, editores e revisores de material.

No mês seguinte a sua inclusão no mercado de fotos, a empresa entrou para o ramo de vídeos em festas universitárias, com a contratação de dois cinegrafistas profissionais, e a realização de um novo investimento, dessa vez em equipamentos de áudio e vídeo. Alguns vídeos podem ser vistos na TV Pridia, sua página do YouTube (www.youtube.com/tvpridia).

Outra fonte de renda da empresa são as parcerias com marcas que desejam se associar aos eventos universitários. Para essas marcas, é importante registrar sua presença nos eventos, por meio de fotos e vídeos das ações que a marca promove, e assim divulgá-las para outras faculdades e ganhar maior penetração e exposição perante o público universitário.

Atualmente a Pridia possui parceria com as três maiores empresas de bebidas alcoólicas do mundo:

- Ambev, com a marca de cerveja Skol;

- Diageo, com a marca de vodka Smirnoff;

- Brown-Forman, com a marca de whisky Jack Daniels;

- Nissin, com a marca de macarrão instantâneo Cup Noodles.

Para o ano de 2014, outras empresas relacionadas já entraram em contato com a Pridia, para contratação de serviços de divulgação e ativação de marcas em eventos universitários. Com a soma dessas duas principais fontes de renda da empresa (fotos e ativações de marcas), seu faturamento ultrapassou o valor de $\mathrm{R} \$ 50$ mil apenas nos últimos cinco meses, e a previsão é de atingir a marca de R\$ 200 mil no ano de 2014, no qual serão focados e expandidos os negócios de gestão de anúncios e produção de vídeos.

\section{A oportunidade de expansão para novos mercados}

O crescimento por meio da expansão para novas áreas de atuação é uma das possibilidades de crescimento. Como a Pridia já mapeou o mercado da Grande São Paulo e vem atuando com sucesso em diversas festas promovidas pelas faculdades de seu público-alvo, agora está em busca de novas oportunidades. Uma alternativa interessante levantada pelos sócios é a expansão para os mercados de Belo Horizonte e/ou Rio de Janeiro.

\section{O mercado universitário no Rio de Janeiro}

Segundo o IBGE, quase $11 \%$ da população do Estado do Rio de Janeiro possui formação com ensino superior. Em todo o Estado, há cerca de 490 mil alunos matriculados em cursos universitários, dos quais 56\% estão na capital (um pouco mais de 273 mil alunos). Trata-se do segundo maior mercado universitário no Brasil, atrás apenas do Estado de São Paulo.

O crescimento desse mercado é intenso, apresentando uma taxa composta de crescimento anual (CAGR) de 5\% entre 1991 e 2007, e aumento de $112 \%$ no número de alunos matriculados em 10 anos. No Estado do Rio de Janeiro, das 78 Instituições de Ensino Superior (IES), 67 são privadas.

Não há dados publicados sobre o mercado de festas universitárias no Rio de Janeiro, mas é possível fazer uma estimativa com base na proporção de alunos matriculados. Na Grande São Paulo, foram mapeadas, segundo a Pridia, em torno de 350 festas universitárias que ocorrem anualmente. Como o mercado universitário no Rio corresponde a 36\% do mercado de São Paulo, então pode-se estimar em torno de 120 a 130 festas universitárias na região da Grande Rio de Janeiro. Além disso, já existe certa relação com importantes clientes de lá, algo conseguido por meio de clientes de São Paulo que possuem uma filial ou correspondente no Estado vizinho. 
PRIDIA: O DESAFIO DA EXPANSÃO DE UMA MICROEMPRESA DE

COBERTURA DE FESTAS UNIVERSITÁRIAS

Kavita Miadaira Hamza

\section{O mercado universitário em Belo Horizonte}

Com relação ao Estado de Minas Gerais, o IBGE aponta que quase $8 \%$ da população possui formação com ensino superior. Em todo o Estado, há cerca de 500 mil alunos matriculados em cursos universitários, dos quais $28 \%$ estão na capital (um pouco mais de 140 mil alunos). Trata-se do terceiro maior mercado universitário no Brasil.

O crescimento desse mercado é intenso, apresentando CAGR de 8\% entre 1991 e 2007, e aumento de $184 \%$ no número de alunos matriculados em 10 anos. Esse é um crescimento maior que o de São Paulo, onde o CAGR é de 6\%, e o aumento em 10 anos foi de 118\%. Das 53 IES da cidade de Belo Horizonte, 47 são privadas.

Não há dados publicados sobre o mercado de festas universitárias em Belo Horizonte, mas é possível fazer uma estimativa com base na proporção de alunos matriculados. Na Grande São Paulo, foram mapeadas, segundo a Pridia, em torno de 350 festas universitárias que ocorrem anualmente. Como o mercado universitário de Belo Horizonte corresponde a 38\% do mercado de São Paulo, então pode-se estimar em torno de 130 a 140 festas universitárias na região da Grande Belo Horizonte.

Assim como no Rio de Janeiro, nesse mercado a Pridia já possui bons contatos com alguns produtores, pois teve a oportunidade de fazer a cobertura fotográfica de um dos maiores eventos de Minas Gerais, o carnaval de Muzambinho (Anexo 6). Com isso, ficou conhecida e inclusive já recebeu alguns convites para cobrir outros eventos.

Ao considerar os dois mercados em conjunto, e assumindo que a Pridia conseguirá manter uma participação de mercado de $50 \%$, chegaria a um potencial de aumento de $43 \%$ no número de festas cobertas. Apesar de ser uma oportunidade interessante para expansão e crescimento, a distância geográfica dos sócios e a consequente necessidade de descentralização da gestão dos negócios nesses novos mercados podem representar potenciais dificuldades para a Pridia.

\section{A oportunidade de criação de uma produtora de festas universitárias}

Enquanto parte das instituições das universidades realiza seus eventos por conta própria, as demais realizam a contratação de agências e produtoras especializadas na produção de eventos, o que inclui desde o planejamento até a execução de todos os fatores necessários, tais como locação de local, decoração, som e luz, artistas, bebidas e comidas, entre outros. Nos casos em que os eventos são terceirizados, são essas agências e produtoras que contratam os serviços de cobertura fotográfica e de vídeo, como os da Pridia.

Trata-se de um mercado interessante. No Brasil, de acordo com o Censo da Educação Superior de 2011, há 2.365 IES, com 6,7 milhões de alunos matriculados e o ingresso de mais 2,3 milhões por ano. Com relação às festas universitárias, quase não há informações disponíveis no mercado. Em levantamento realizado pelos sócios da Pridia, ao analisar apenas a região da Grande São Paulo (atual área de atuação da Pridia), são realizadas cerca de 350 festas universitárias a cada ano, com um público médio de 800 pessoas, e ticket de entrada de $\mathrm{R} \$ 70,00 /$ pessoa, resultando em um faturamento anual em torno de $\mathrm{R} \$ 20$ milhões.

Atualmente, o mercado conta com seis empresas principais, e a tendência do mercado tem sido de concentração, com a redução para de duas a quatro empresas no futuro. Isso ocorre porque algumas já estão migrando para o mercado de formaturas e de eventos corporativos, e também devido à queda de credibilidade de outras empresas. Entre as produtoras com atuação no mercado universitário em São Paulo, as principais são apresentadas no Anexo 7. Na classificação do "Porte", foi usada como critério a quantidade semestral de eventos realizados, e na "Credibilidade" foram usados a percepção e os comentários de clientes e parceiros.

As inovações nesse mercado vêm exigindo a incorporação de novos elementos tecnológicos, como opções on-line e mobile para a compra de ingressos, avançados sistemas de comunicação interna para a equipe de produção, produtos designados ao aumento da interação com os clientes 
PRIDIA: O DESAFIO DA EXPANSÃO DE UMA MICROEMPRESA DE COBERTURA DE FESTAS UNIVERSITÁRIAS

Kavita Miadaira Hamza

durante o evento (como a geladeira premiada da Skol, do Anexo 8), além da divulgação nas redes sociais. Ademais, é importante destacar o constante aumento do poder de consumo desses jovens. $\mathrm{O}$ ticket médio de entrada nas festas, por exemplo, mais do que dobrou nos últimos 10 anos.

Levando em consideração o tamanho do mercado, a concorrência entre os players e o knowhow e networking adquiridos ao longo dos meses pelos três jovens, pode-se prever o seguinte cenário para a produtora:

6 meses:

Funcionários: 4 fixos +150 sob demanda

Quantidade semestral de eventos: 6

Faturamento semestral aproximado: R \$ 80.000,00

12 meses:

Funcionários: 6 fixos +200 sob demanda

Quantidade semestral de eventos: 10

Faturamento semestral aproximado: R \$ 150.000,00

18 meses:

Funcionários: 8 fixos +250 sob demanda

Quantidade semestral de eventos: 15

Faturamento semestral aproximado: R \$ 200.000,00

Tendo em vista essa oportunidade para verticalizar a empresa e inseri-la nesse segmento da produção, a empresa Pridia pode ampliar sua estrutura e ser bem-sucedida nesse aspecto. Por outro lado, no momento em que a empresa passar a produzir eventos, outras produtoras (que atualmente são clientes da Pridia) se tornarão concorrentes nessa segunda esfera, e isso pode prejudicar a relação da atividade primária realizada pela empresa atualmente. A imagem do Anexo 9 apresenta esse potencial conflito que pode ser gerado.

\section{O desafio do crescimento}

Como todas as empresas, a Pridia deseja expandir seu negócio e se tornar uma empresa de sucesso no ramo de festas universitárias. O crescimento por meio da expansão para novas áreas de atuação é uma das alternativas. Como a Pridia já mapeou o mercado da Grande São Paulo e vem atuando com sucesso em diversas festas promovidas pelas faculdades de seu público-alvo, agora está em busca de novas oportunidades de crescimento.

Nas últimas semanas, os sócios levantaram muitas informações de mercado e identificaram duas grandes oportunidades, conforme apresentado anteriormente: (i) expandir o negócio para outras cidades (Rio de Janeiro e/ou Belo Horizonte) ou (ii) integrar a cadeia de valor, criando uma nova empresa, especializada na produção de festas universitárias.

Seria ótimo poder aproveitar todas as oportunidades de mercado, mas a empresa ainda é pequena e tem sua gestão centralizada nos três sócios fundadores. Eles sabem que, se tentassem abarcar as duas propostas, poderiam perder a alta qualidade de seu negócio atual, que já tem uma boa reputação de mercado e que atualmente produz um importante fluxo de caixa para sua manutenção. 
PRIDIA: O DESAFIO DA EXPANSÃO DE UMA MICROEMPRESA DE COBERTURA DE FESTAS UNIVERSITÁRIAS

Kavita Miadaira Hamza

\section{Anexo 1}

Diferença de qualidade entre fotos tiradas em uma mesma festa universitária, por um concorrente (à esquerda) e pelos profissionais da Pridia (à direita)

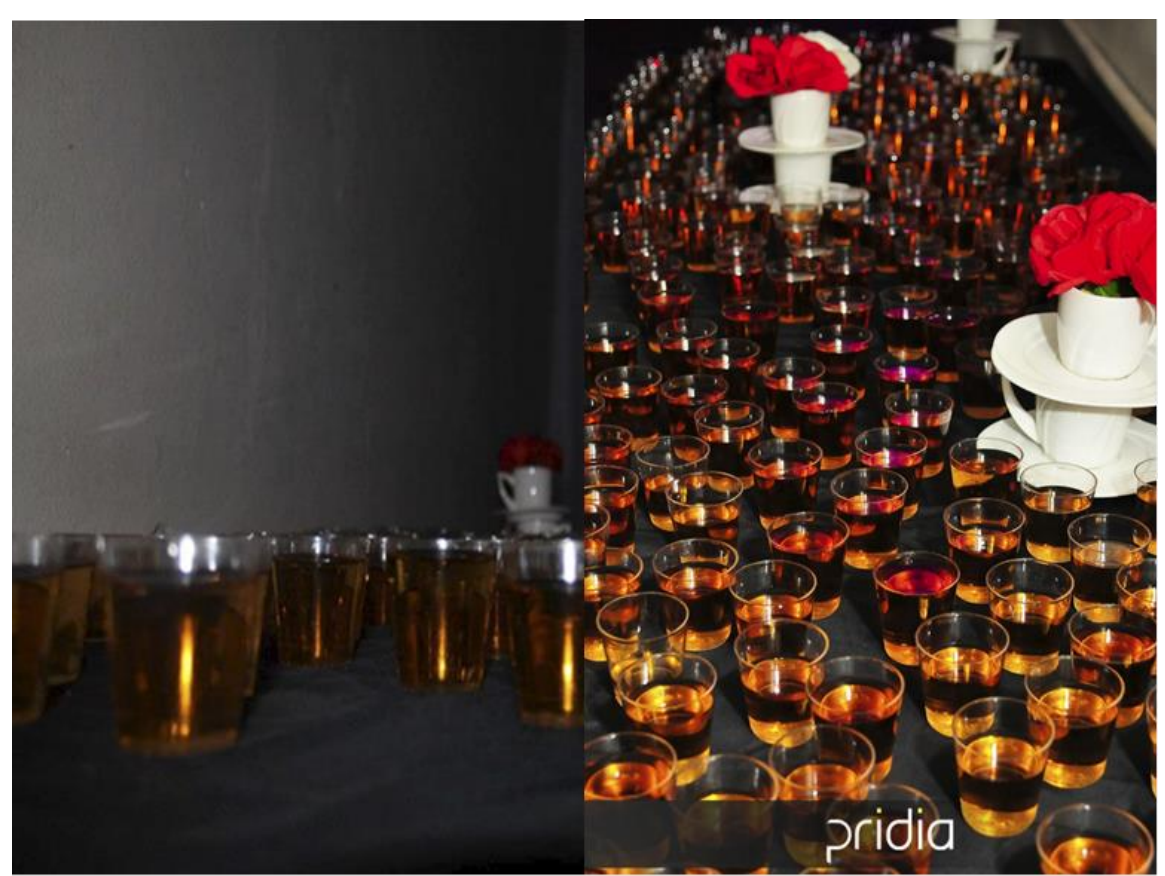

Anexo 2

Diferença de qualidade entre fotos tiradas em uma mesma festa universitária, por um concorrente (à esquerda) e pelos profissionais da Pridia (à direita)

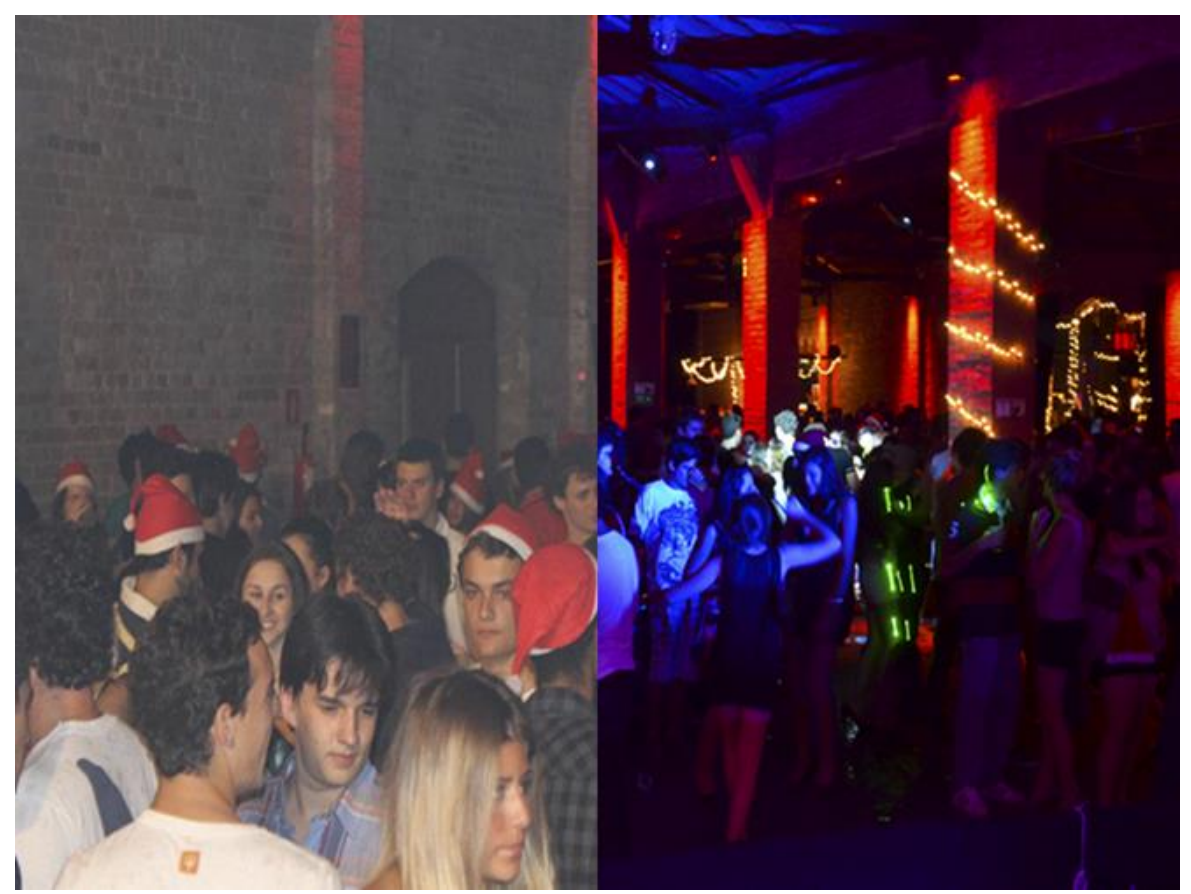


PRIDIA: O DESAFIO DA EXPANSÃO DE UMA MICROEMPRESA DE COBERTURA DE FESTAS UNIVERSITÁRIAS

Anexo 3

Número de eventos cobertos pela Pridia em 2013

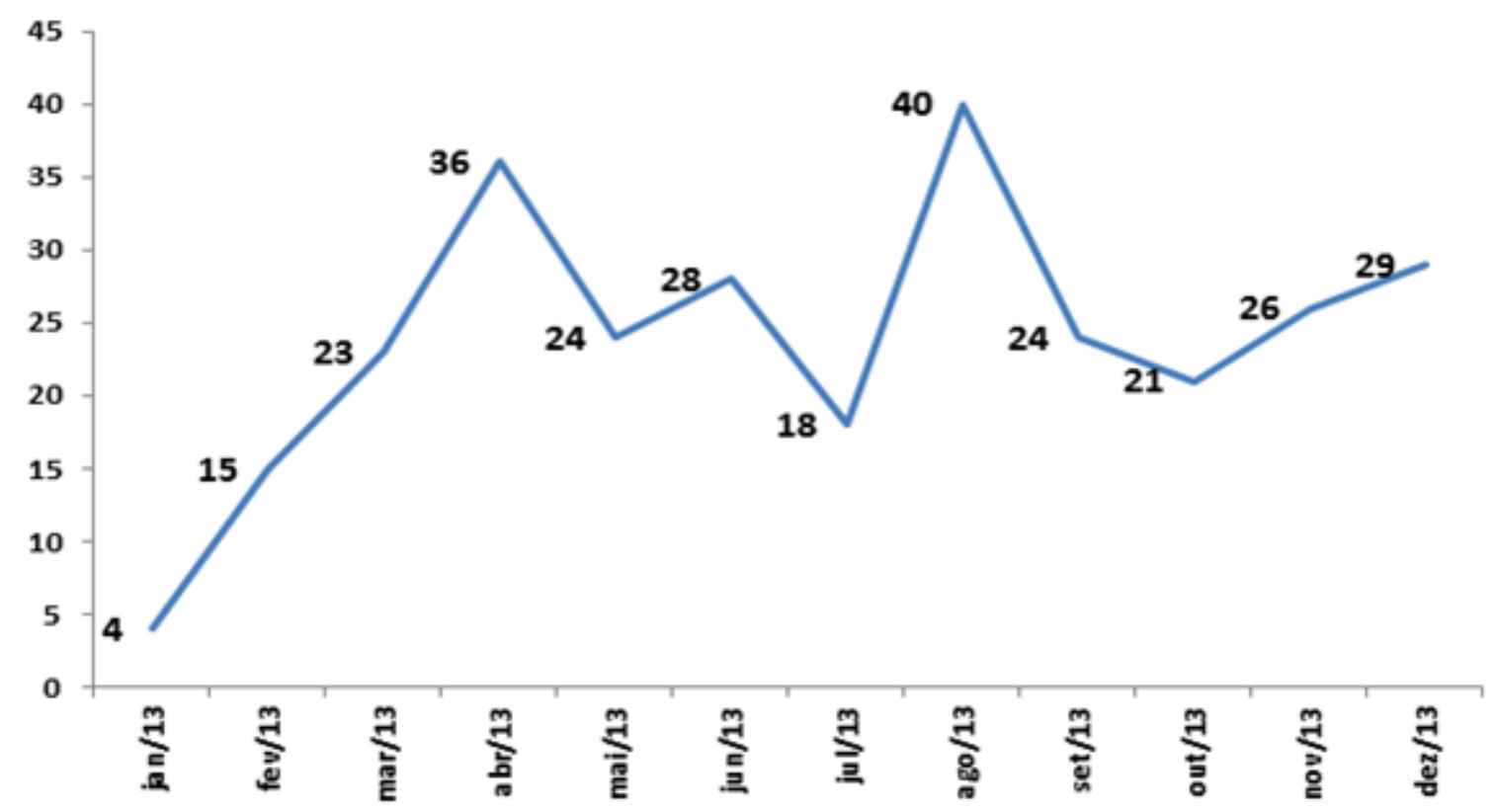

Anexo 4

Participação de mercado da Pridia e de seus concorrentes nos anos de 2012 e 2013

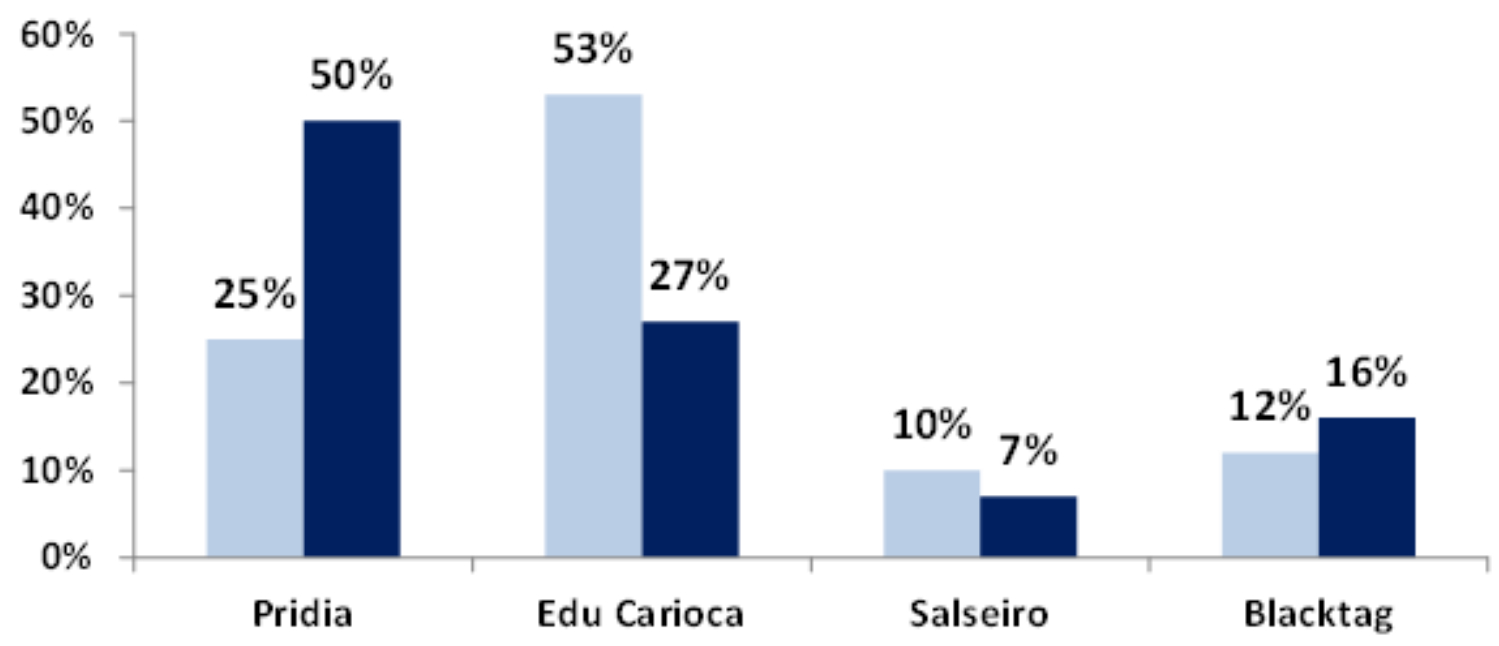


PRIDIA: O DESAFIO DA EXPANSÃO DE UMA MICROEMPRESA DE COBERTURA DE FESTAS UNIVERSITÁRIAS

\section{Anexo 5}

Evolução do número de usuários na fanpage da Pridia em 2013

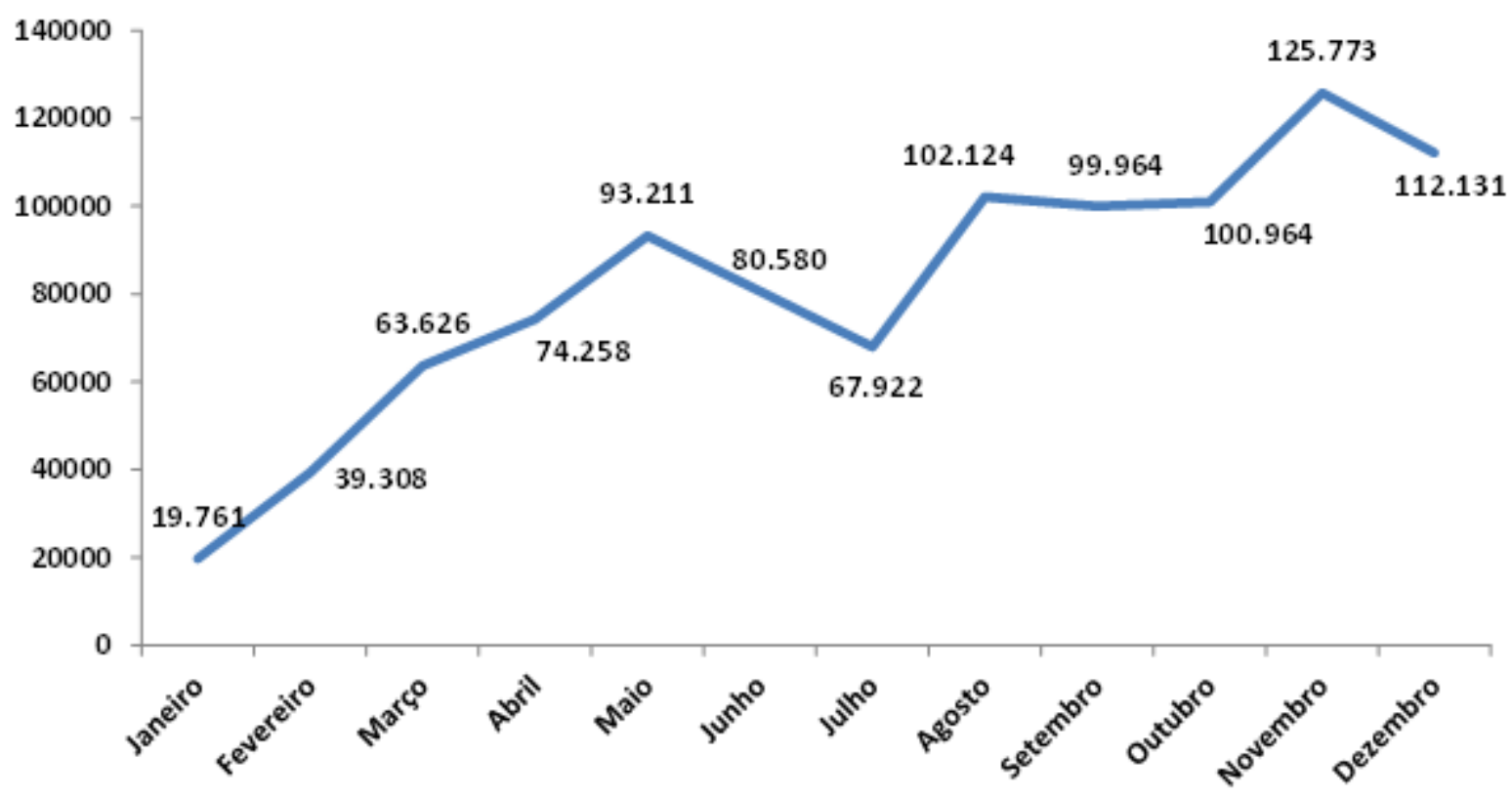

Anexo 6

Foto feita pela Pridia na cobertura do carnaval de Muzambinho, um dos maiores eventos de Minas Gerais

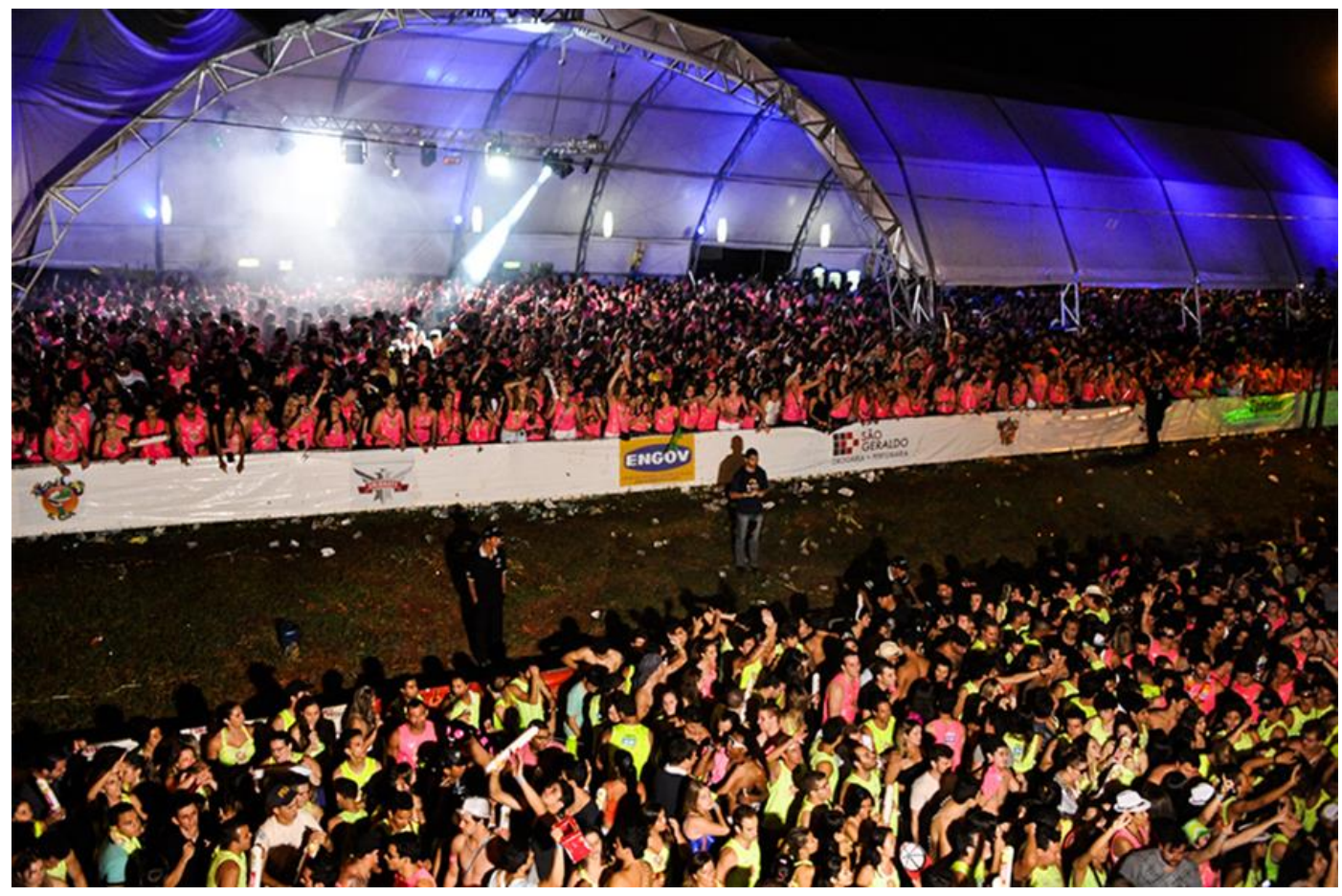


PRIDIA: O DESAFIO DA EXPANSÃO DE UMA MICROEMPRESA DE

COBERTURA DE FESTAS UNIVERSITÁRIAS

Kavita Miadaira Hamza

\section{Anexo 7}

Produtoras de festas no mercado universitário

\begin{tabular}{|c|c|c|c|c|c|c|c|c|}
\hline Empresa & Fundação & Porte & Público & Mercado & Credibilidade & Situação atual & Fanpage & Site \\
\hline $\begin{array}{l}\text { BM9 } \\
\text { Eventos }\end{array}$ & 2003 & Grande & $\mathrm{A}$ e B & $\begin{array}{l}\text { Festas } \\
\text { universitárias }\end{array}$ & Média & $\begin{array}{l}\text { A empresa atualmente encontra-se em um período de } \\
\text { declínio, perdendo muitos clientes para suas concorrentes } \\
\text { pelo fato de não realizar nenhum tipo de inovação em } \\
\text { seus eventos, apenas mantendo seu padrão médio de } \\
\text { desempenho. }\end{array}$ & $\begin{array}{l}\text { https://www.facebo } \\
\text { ok.com/bm9eventos }\end{array}$ & $\begin{array}{l}\text { http://bm9eve } \\
\text { ntos.com.br/ }\end{array}$ \\
\hline $\begin{array}{l}\text { UFO } \\
\text { Eventos }\end{array}$ & 1999 & Médio & $\mathrm{AA}$ e $\mathrm{A}$ & $\begin{array}{l}\text { Festas } \\
\text { universitárias }\end{array}$ & Média & $\begin{array}{l}\text { Fortemente estabelecida perante seus clientes, a empresa } \\
\text { não enfrenta grandes riscos, mas também não pretende } \\
\text { buscar novas oportunidades para uma eventual expansão. }\end{array}$ & & $\begin{array}{l}\text { http://www.u } \\
\text { foeventos.co } \\
\text { m.br/ }\end{array}$ \\
\hline $\begin{array}{l}\text { Mandi } \\
\text { Eventos }\end{array}$ & 2004 & Médio & $\mathrm{AA}$ e $\mathrm{A}$ & $\begin{array}{l}\text { Festas } \\
\text { universitárias e } \\
\text { eventos } \\
\text { corporativos }\end{array}$ & Alta & $\begin{array}{l}\text { A empresa passa atualmente por um processo de } \\
\text { migração que consiste em se afastar do mercado de festas } \\
\text { universitárias e promover um foco nos eventos } \\
\text { corporativos. Concomitantemente, um alto padrão de } \\
\text { qualidade é presente em todas as suas realizações. }\end{array}$ & & \\
\hline $\begin{array}{l}\text { TOP } \\
\text { Entreteni } \\
\text { mento }\end{array}$ & 2008 & Grande & $\mathrm{A}$ e B & $\begin{array}{l}\text { Festas } \\
\text { universitárias e } \\
\text { formaturas }\end{array}$ & Baixa & $\begin{array}{l}\text { Após muitos casos e acusações de atividades ilícitas, a } \\
\text { empresa possui uma credibilidade muito baixa em relação } \\
\text { aos seus clientes e parceiros, porém o impacto desses } \\
\text { erros não abalou por completo a estrutura da empresa, } \\
\text { que ainda conta com uma grande quantidade de eventos e } \\
\text { clientes. }\end{array}$ & $\begin{array}{l}\text { https://www.facebo } \\
\text { ok.com/topentreteni } \\
\text { mento }\end{array}$ & $\begin{array}{l}\text { http://www.t } \\
\text { opentretenim } \\
\text { ento.com.br/ }\end{array}$ \\
\hline $\begin{array}{l}\text { WN } \\
\text { Eventos }\end{array}$ & 2011 & Médio & $\mathrm{B}$ e C & $\begin{array}{l}\text { Festas e jogos } \\
\text { universitários }\end{array}$ & Média & $\begin{array}{l}\text { Por ser uma empresa recente, ela passa atualmente por } \\
\text { uma fase de adaptação ao mercado, na qual ainda procura } \\
\text { encontrar seu ponto de atuação principal, que é dividido } \\
\text { em festas e jogos universitários, porém nenhum deles } \\
\text { ainda com uma relevância muito alta em relação aos } \\
\text { concorrentes. }\end{array}$ & $\begin{array}{l}\text { https://www.facebo } \\
\text { ok.com/CurtaWNEv } \\
\text { entos }\end{array}$ & $\begin{array}{l}\text { http://www.w } \\
\text { neventos.com } \\
\text { / }\end{array}$ \\
\hline Maker & 2012 & Grande & $\mathrm{B}$ e $\mathrm{C}$ & Festas e shows & Média & $\begin{array}{l}\text { Com recentes problemas burocráticos e legais em seus } \\
\text { eventos, a empresa sofreu uma sensível perda de } \\
\text { credibilidade, mas nada a ponto de prejudicar sua } \\
\text { estrutura total de clientes e fornecedores. Seus eventos } \\
\text { continuam de grande porte, principalmente nos recentes } \\
\text { casos em que está se aliando a sua até então concorrente } \\
\text { WN Eventos. }\end{array}$ & $\begin{array}{l}\text { https://www.facebo } \\
\text { ok.com/agenciamak } \\
\text { er }\end{array}$ & $\begin{array}{l}\text { http://www.a } \\
\text { genciamaker. } \\
\text { com.br/ }\end{array}$ \\
\hline
\end{tabular}


PRIDIA: O DESAFIO DA EXPANSÃO DE UMA MICROEMPRESA DE COBERTURA DE FESTAS UNIVERSITÁRIAS

\section{Anexo 8}

Geladeira premiada da Skol

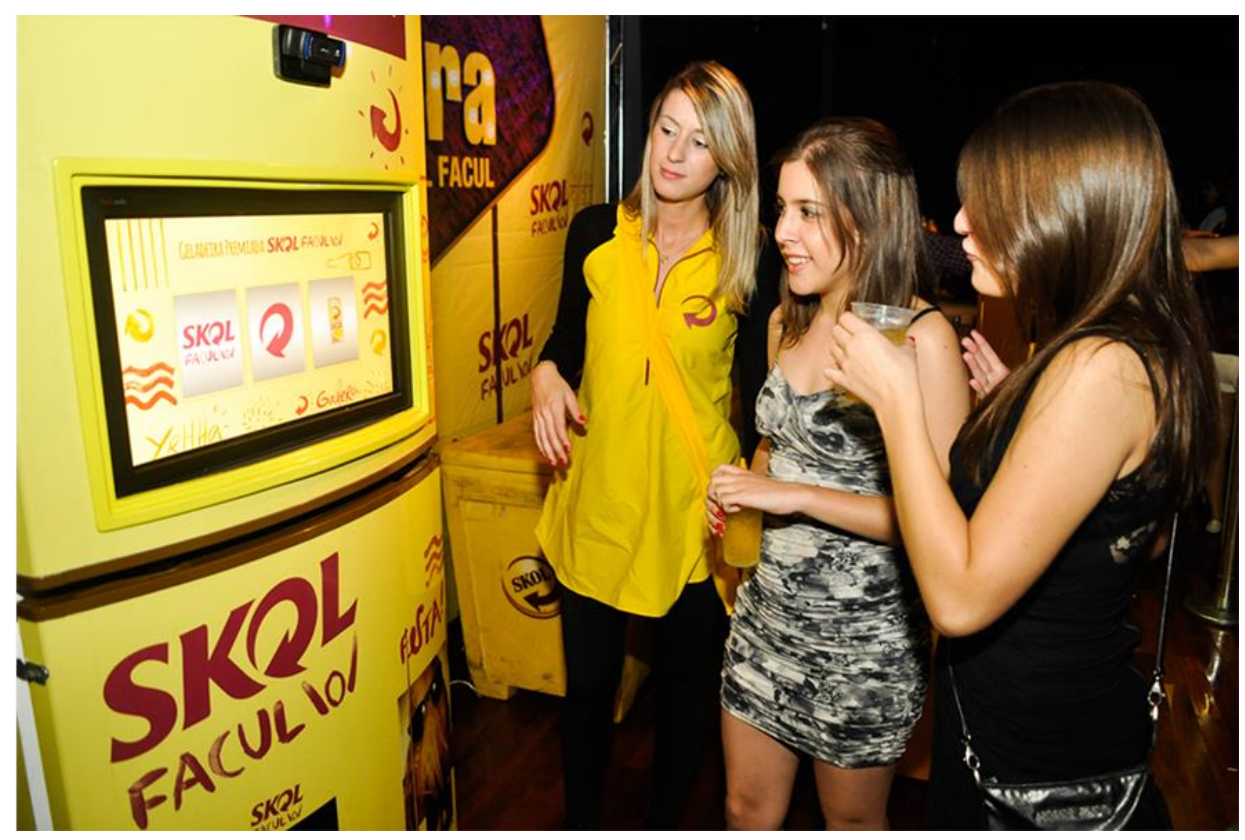

\section{Anexo 9}

Potencial conflito no mercado de produção de festas universitárias

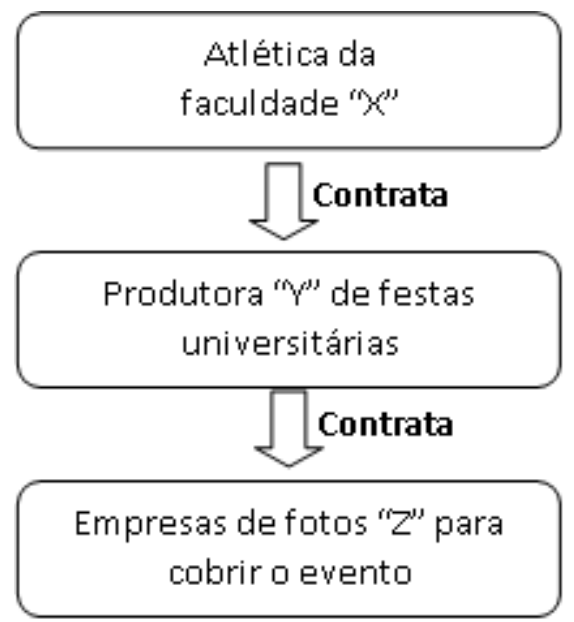

Pridia concorre com essa produtora para conseguir este contrato de prestação de serviço.

Como a Pridia passa a ser concorrente na atividade anterior, a Produtora " $x$ " pode decidir nẵo mais contratar os seus serviços de cobertura fotográfica e de vídeo. 